\title{
Preparation, characterization and rheological behavior of chitosan nanocapsule emulsion encapsulated tuberose fragrance
}

\author{
Zuobing Xiao, Erqin Wang, Guangyong Zhu*, Rujun Zhou, Yunwei Niu \\ Shanghai Institute of Technology, Shanghai, 201418, PR China \\ "Corresponding author: e-mail: gyz@sit.edu.cn
}

\begin{abstract}
In this paper, ionic gelation method was adopted to produce nanocapsules $(\mathrm{CNs})$ encapsulated tuberose fragrance with chitosan (CS) and sodium tripolyphosphate (TPP) as wall materials. The effects of CS/TPP mass ratio, $\mathrm{pH}$ value of CS solution, molecular mass of CS and tuberose fragrance (TF) concentration on particle size and particle size distribution (PDI) of chitosan nanocapsules encapsulated tuberose fragrance (CNTs) were investigated systematically. CNTs were characterized by dynamic light scattering (DLS), scanning electron microscopy (SEM), Fourier transforms infrared spectroscopy (FTIR), X-ray diffraction (XRD), thermogravimetric analyzer (TGA) and differential scanning calorimetry (DSC). The results showed that CNTs were successfully prepared. The optimum preparation conditions were as follows: CS/TPP mass ratio 5:1, $\mathrm{pH}$ of CS solution 4.0, and molecular mass of CS $150 \mathrm{kda}$. CNTs emulsions were also systematically investigated by steady-state shear and oscillatory shear measurements respectively. The rheological behaviors of CNTs were obtained.
\end{abstract}

Keywords: chitosan nanocapsules, encapsulation, rheological, viscoelasticity, particle size.

\section{INTRODUCTION}

Microencapsulation is a technique of packing the sensitive ingredients within a coating or wall material (usually polymers) to protect them from physico-chemical effects of the surrounding medium ${ }^{1}$. Nanocapsule is a new kind of microcapsule with nanometer size. Polymer nanocapsules compared with the ordinary microcapsule has special advantages and unique properties, and has received much attention of scholars ${ }^{2,3}$. Because particle size is small, nanoparticles is easy to disperse, and has more broad application prospects than traditional microcapsules. Nanoencapsulation can entrap liquid fragrance in a capsule or membrane, and physically separate the substance from the deteriorating circumstance, so it can solve the problems that liquid fragrance is highly volatile and chemically labile as a result of oxidation, chemical interactions, or volatilization in the presence of oxygen, light, water and heat ${ }^{4}$. Chitosan, a natural plentiful biopolymer obtained by chitin deacetylation, mainly consists of the repeating unit of 2-amino- and 2-acetamido-2-deoxy- $\beta$-D-glucopyranose. Due to its unique properties such as favorable biological properties ${ }^{5}$, antimicrobial activity $^{6}$, low toxicity, biodegradability ${ }^{7}$ and proper mucoadhesive properties ${ }^{8}$, Chitosan has been extensively applied in various fields, such as biotechnology ${ }^{9}$, food ingredients ${ }^{10}$, pharmaceuticals ${ }^{11}$, waste water treatment ${ }^{12}$ and cosmetics ${ }^{13}$. Sodium tripolyphosphate is an anionic cross-linker. It exhibits non-toxicity and quick gelling ability that make it a favorable cross-linker for ionic gelation of chitosan. TPP affords electrostatic binding via ionic interactions between the positively charged amino groups of chitosan and the negatively charged counter ions of $\mathrm{TPP}^{14,15}$. There are many kinds of preparation methods of nanocapsules, however, the ionic gelation method is simple, mild, scalable, low cost, organic solventfree and reproducible to obtain nanocapsulation. In this paper, ionic gelation method was adopted to produce CNs encapsulated tuberose fragrance with chitosan CS and TPP as wall materials.

Nanofluids ${ }^{16}$ are two-phase mixtures composed of very fine particles in suspension in a continuous and satu- rated liquid (water, ethylene glycol, engine oil) ${ }^{17}$. Bulk rheological properties of nanofluids (shear viscosity and complex modulus ${ }^{18}$ can be important factors for some applications ${ }^{19}$. Rheology is the science concerns with the flow and deformation characteristics of liquid or semi-solid materials under an applied force, in particular, to their behaviors in the transient area between solids and fluids. Moreover, rheology attempts to define a relationship between the stress acting on a given material and the resulting deformation and/or flow that takes place. The rheology has acquired broad applications in numerous fields including food, cosmetics, perfumery and paint industry. Besides, rheological data provide information related to flow behavior of liquid or semi-solid material and are used in quality control, energy calculation for process control and equipment selection in the industry. The rheological behavior has significance to nanofluids stability and flow behavior ${ }^{20}$. Many research efforts reveal that the particle size of nanofluids influence its rheological properties to a large extent ${ }^{21}$.

Because of the influence of reaction conditions in the process of preparation, the rheological properties of nanocapsules emulsion system are different. Although there are a large body of rheology literatures on suspensions and/or colloids ${ }^{22}$, There is a very small amount of work dedicated to the rheological behavior of nanocapsule emulsion. In this paper, the method of study on the rheological properties of the suspensions and/or colloids was adopted to investigate the rheological properties of nanocapsule emulsion. The relationship between the rheological properties and particle size of nanocapsules was investigated.

\section{MATERIAL AND METHODS}

\section{Material}

Chitosan (average molecular weight: $50 \mathrm{kda}, 150 \mathrm{kda}$, $450 \mathrm{kda}$, degree of deacetylation 90\%) was purchased from Golden-Shell Biochemical Co., Ltd. (Yuhuan, Zhejiang, China). Sodium tripolyphosphate, sorbitan monostearate (Span 60), and polyoxyethylenesorbitan 
trioleate (Tween 80) was purchased from Sinopharm Chemical Reagent Co., Ltd (Shanghai, China). All the above reagents used were of analytical grade. Tuberose fragrance was blended in our laboratory.

\section{Preparation of nanocapsule emulsion}

CS and TPP were adopted as wall materials. CNTs were prepared in oil/water $(\mathrm{o} / \mathrm{w})$ emulsion using the ionic gelation method. The production steps of CNTs emulsion were as follows: CS was dissolved in $1 \%(\mathrm{w} / \mathrm{w})$ acetic acid aqueous solution and was ultrasonicated at $800 \mathrm{~W}$ for 10 min using ultrasonic cell disruptor (JY92-2D). Then, sodium hydroxide aqueous solution was added gradually to adjust the $\mathrm{pH}$ in the range of 3.5 to 5.5 , and to form wall material solution. Mixtures of $\mathrm{TF}(0.2,0.4$, $0.6,0.8 \%)$, emulsifier $(0.03 \%$ Span 60 and $0.17 \%$ Tween 80 ) and TPP aqueous solution were ultrasonicated at $800 \mathrm{~W}$ for 10 min using ultrasonic cell disruptor (JY92-2D) to form core material emulsion. The core material emulsion was added dropwise to wall material solution at a rate of 1 drop $/ 3$ second using peristaltic pump. At the same time, wall material solution was stirred at a rate of $800 \mathrm{rpm}$ throughout the process. The concentration of wall material (CS/TPP mass ratios ranging from 3:1 to $8: 1$ ) was $0.18 \%$. The mixture was stirred at $800 \mathrm{rpm}$ for further $30 \mathrm{~min}$ by magnetic stirring.

\section{Dynamic light scattering}

The particle size and the polydispersity index (PDI) of CNTs were determined by Zetasizer Nano ZS (Malvern Instruments, Worcestershire, UK). Each sample measurement was done via a solid state $\mathrm{He}-\mathrm{Ne}$ laser of $633.0 \mathrm{~nm}$ at $25^{\circ} \mathrm{C}$ with an angle detection of $90^{\circ}$. All of the measurements were performed in triplicate, and the results are reported in terms of mean diameter \pm SD.

\section{Scanning electron microscopy}

Scanning electron microscopy was used to investigate the morphology of nanocapsules. The SEM analysis of the microspheres was carried out by using a Hitachi S$-3400 \mathrm{~N}$ scanning electronic microscope (Hitachi, Japan) at an accelerated voltage of $15 \mathrm{kV}$ under high vacuum. One drop of the nanoparticle emulsion was dropped on the mental stub which was covered with double sided tape. Nanoparticle samples were coated with gold sputter coater in a high vacuum evaporator ${ }^{23}$.

\section{Fourier transforms infrared spectroscopy}

The chemical structures of TF, CNTs and CNs were determined with a VERTEX 70 FTIR spectrophotometer (Bruker, Ettlingen, Germany) in the range from 4000 to $600 \mathrm{~cm}^{-1}$. The interactions between TF, TPP and CS were characterized by the infrared spectra.

\section{X-ray diffraction}

XRD patterns of CNTs and CNs were obtained by an X-ray diffractiometer (PW3040/60, PANalytical B.V, Netherlands). The patterns were recorded in the region of $2 \theta$ from 5 to $80^{\circ}$ with $\mathrm{Cu}-\mathrm{K}_{\alpha}$ irradiation at $37.5 \mathrm{kV}$ and $20 \mathrm{~mA}$.

\section{Thermogravimetric and differential scanning calorimetry diagram}

Thermogravimetric characteristics of TF, CNTs and CNs were determined with a thermogravimetric analyser TGA-Q5000IR (TA Instruments, USA). About 5mg of microcapsule samples were weighed and heated at $10^{\circ} \mathrm{C} /$ min from 20 to $800^{\circ} \mathrm{C}$ under a constant nitrogen flow (20 $\mathrm{ml} / \mathrm{min})$.

\section{Rheological properties}

AR-G2 Rheometer (TA Instrument, US) was used to measure rheological properties of CNTs emulsion. The measuring configuration adopted was a concentric coaxial cylinder. Steady and dynamic rheology properties of CNTs emulsion were carried out at $25^{\circ} \mathrm{C}$. Any heat generated by the shearing process was dissipated into the surrounding water bath.

\section{Steady rheological measurements}

In the steady shear measurement, a certain amount of CNTs emulsion was added in the interspace between concentric coaxial cylinders and allowed to come to thermal equilibrium for 3 min before rheological experiments were made. Data were collected by "stepped flow step" mode. The range of shear rate $\left(\mathrm{S}^{-1}\right)$ was $0.001 \sim 1000$. In logarithmic mode scanning, changing of apparent viscosity with the shear rate was determined.

\section{Strain sweep measurement}

The strain sweep experiment, in which an applied strain at one frequency was gradually increased, was performed for each particle size of the of nanocapsules emulsion to ensure operation in the linear viscoelastic region (LVR). The critical strain amplitude was firstly determined, typically $1-5 \%$ strain, and then a frequency sweep experiment was performed.

\section{Frequency sweep measurement}

The frequency sweep measurement was further carried out within LVR at $1 \%$ strain to obtain more precise information on emulsion stability. A certain amount of CNTs emulsion was added in the interspace between concentric coaxial cylinders and allowed to come to thermal equilibrium for $3 \mathrm{~min}$ before rheological experiments were made. Test temperature was set at $25^{\circ} \mathrm{C}$. Data were collected by "frequency sweep step mode". The range of shear velocity (as variables) was $0.001 \sim$ $1000 \mathrm{rad} / \mathrm{s}$. In logarithmic mode scanning, the complex modulus $G^{*}$, the storage (or elastic) modulus $G^{\prime}$, and the loss (or viscous) modulus G" were determined ${ }^{24}$.

\section{RESULTS AND DISCUSSION}

\section{The particle size and particle size distribution}

\section{Effect of CS-TTP Mass Ratio}

Different concentrations of CS and TPP were used to determine the optimum CS/TPP ratios (CS/TPP mass ratios ranging from $3: 1$ to $8: 1$ ). $\mathrm{CS} / \mathrm{TPP}$ mass ratio significantly influences the particle size and particle size distribution of CS-TPP nanoparticles. The changes of particle size and PDI with the increasing of CS/TPP 
mass ratio from 3:1 to 8:1 were shown in Figure 1(a). It appeared that the optimum CS/TPP ratio among these samples was 5:1. It is known that the ability of CS to quickly gel on contact with TPP relies on the formation of inter- and intramolecular crosslinking between the amino groups and the phosphate groups. As CS-TPP mass ratio declined from $5: 1$ to $3: 1$, the available quantity of TPP increased and the superfluous TPP would link the monoparticles to form larger nanoparticles ${ }^{25}$. As CS-TPP mass ratio increased from $5: 1$ to $8: 1$, the formation of the linkage or aggregation of the nanoparticles might be caused.

\section{Effect of pH Value of CS Solution}

As a weak base polysaccharide, CS is insoluble at neutral and alkaline solutions. Figure 1(b) shows the effect of $\mathrm{pH}$ value of CS solution on size and PDI. The smallest particle sizes occurred at $\mathrm{pH}$ 4.0. The size decreased with the increase of $\mathrm{pH}$ values from 3.5 to 4.0. When the $\mathrm{pH}$ value is 3.5 , a stronger intramolecular repulsion may be caused by the stronger protonation. This makes the CS chain stretch and results in larger nanoparticles. Afterward, the particle size increased as the $\mathrm{pH}$ value rose from 4.0 to 5.5 . The comparatively weak

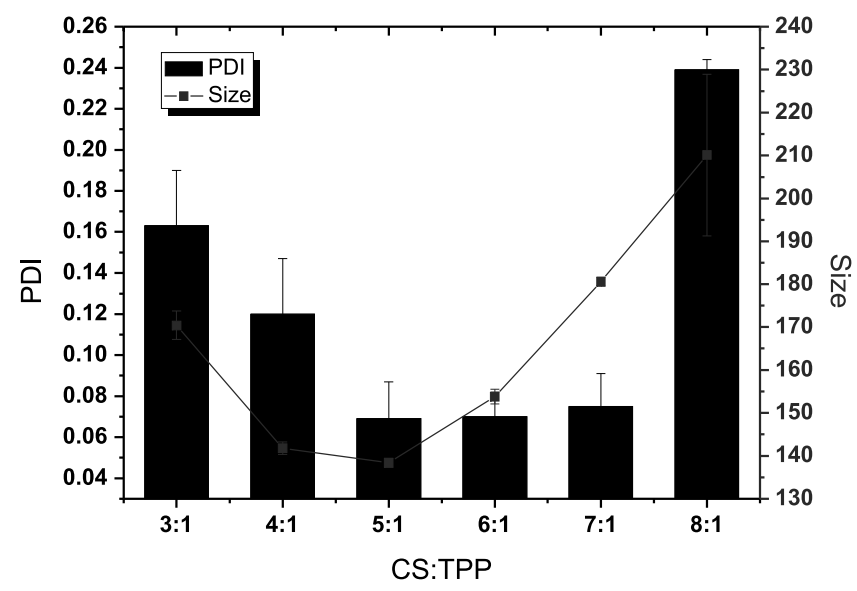

(a)

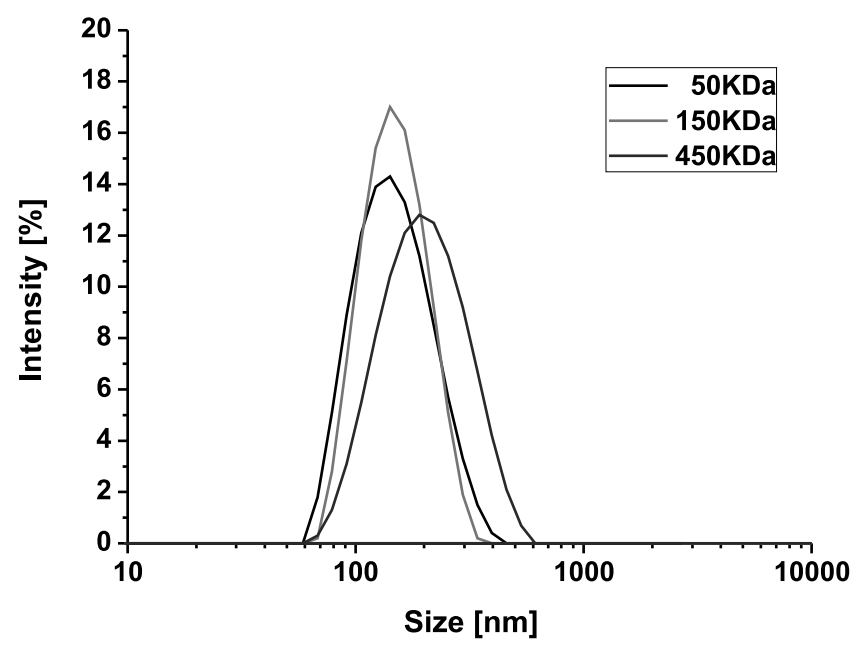

(c) interaction between CS and TPP led to the formation of larger nanoparticles ${ }^{\mathbf{2 6}}$. However, the heterogeneity became higher and higher as $\mathrm{pH}$ increased, which may also be related to the CS solubility.

\section{Effect of CS Molecular Mass}

The particle size distributions obtained by DLS for different CS molecular mass are shown in Figure 1(c). The data of particle size showed a trend of normal distribution. Distribution of particle size was monodispersity. The change of particle size with CS molecular mass was not obvious. With the increase of molecular mass, particle size had a tendency to increase. It can be presumed that the length of the CS molecule is too long to be sheared to degrade into small fragments engaged in the formation of CS-TPP nanoparticles.

\section{Effect of TF Concentration}

The particle size distributions obtained by DLS for different TF concentration are shown in Figure 1(d). It indicates that the particle size increase with the increasing of TF concentration. The main reason for these results may be that a higher concentration of core material forms larger sized particles during emulsion process of

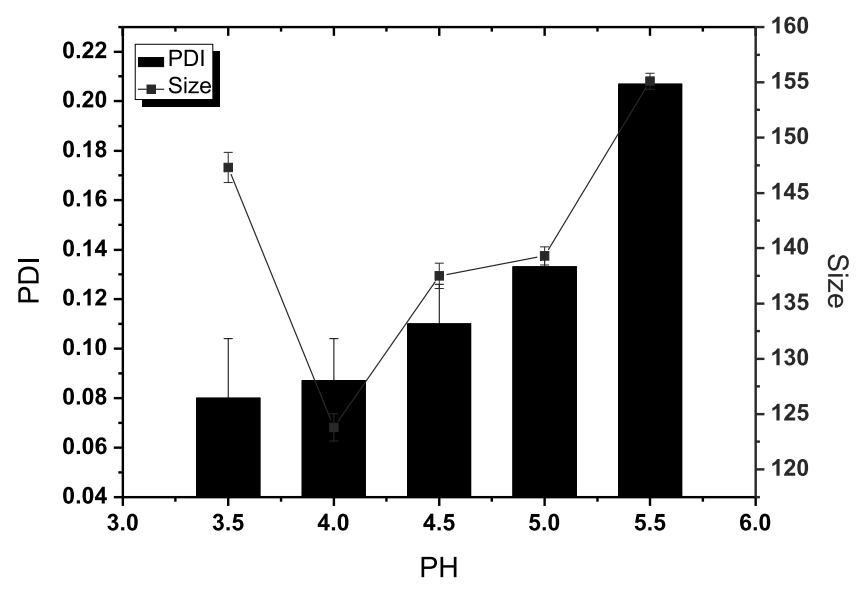

(b)

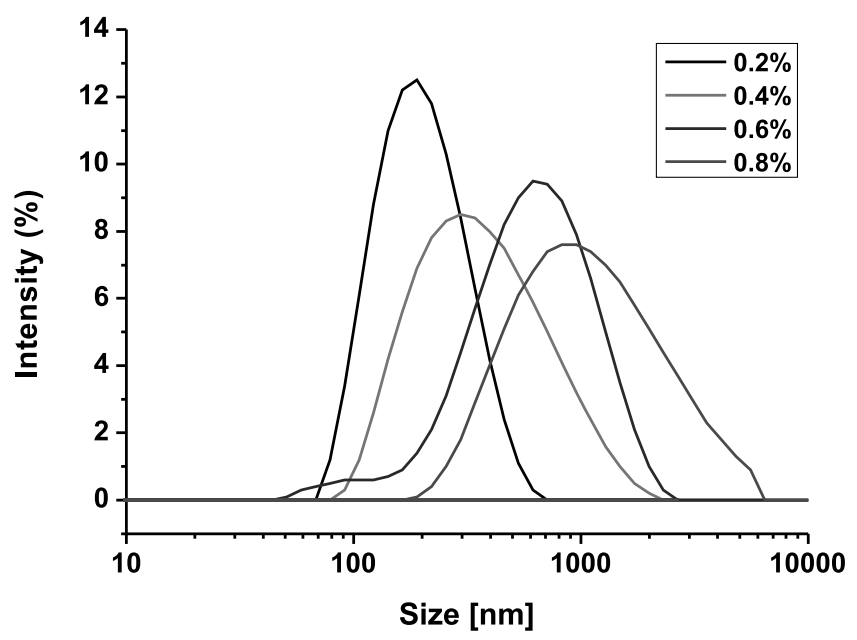

(d)

Figure 1. (a) Effect of CS-TTP Mass Ratio on the Size and PDI of the CNTs, (b) Effect of pH Value of CS Solutionon on the Size and PDI of the CNTs, (c) Effect of CS Molecular Mass on particle size distributions of the CNTs, (d) Effect of TF Concentration on particle size distributions of the CNTs 
core material, and promote the increase of the particle size of nanocapsules ultimately.

\section{Particle Micromorphology}

SEM was used to study the appearance of the nanocapsules. The SEM micrographs of nanocapsules were shown in Figure 2. It showed that the nanocapsules almost were spherical in shape. Distribution of particle size was uniform comparatively.

\section{FTIR analysis}

The structure characteristics of the nanocapsules were determined through infrared spectrum. FTIR spectra of TF, CNTs and CNs were shown in Figure 3(a). It showed that the specific absorption peaks of CNTs and CNs were very similar. Characteristic absorptions of sample cover the whole of $500 \sim 4000 \mathrm{~cm}^{-1}$ area. The bands at 2967 $\mathrm{cm}^{-1}, 2864 \mathrm{~cm}^{-1}, 1727 \mathrm{~cm}^{-1}, 1270 \mathrm{~cm}^{-1}, 756 \mathrm{~cm}^{-1}$ and $697 \mathrm{~cm}^{-1}$, represent characteristic absorptions of $-\mathrm{OH}$, $\mathrm{C}-\mathrm{H}, \mathrm{C}=\mathrm{O}, \mathrm{C}-\mathrm{O}$ and $\mathrm{C}-\mathrm{C}$ stretching respectively. After TF was encapsulated, the characteristic absorption peaks at $1727 \mathrm{~cm}^{-1}$ and $1270 \mathrm{~cm}^{-1}$ disappeared, and the band at $1094 \mathrm{~cm}^{-1}$ appeared due to multiple absorption of $\mathrm{P}-\mathrm{O}$ vibration and $-\mathrm{NH}_{2}$ deformation stretching vibration. This was attributed to the crosslinking effect of phosphoric acid root and the protonation of amino ${ }^{27}$. Peak type of CNTs and CNs was similar. From the peak shape and peak position, it can be inferred that TF was encapsulated in the wall materials.

\section{$X$-ray diffraction analysis}

X-ray diffraction (XRD) experiment was carried out to gain an insight into the internal structure of the CNTs and CNs. The XRD of the CNTs and CNs were shown in Figure 3(b). It showed that the intensities of CNTs and CNs were different. When $2 \theta$ is $20.05^{\circ}$, the maximum intensity of CNTs is 792 (a.u.), while intensity of CNTs reached 1118 (a.u.). This may be caused by the TF encapsulated in the wall materials.

\section{Thermal stability analysis}

The TG curves of CNTs and CNs were shown in Figure 4(a). The weight loss of CNTs and CNs was about $4.71 \%$ from 30 to $157^{\circ} \mathrm{C}$, which mainly due to evaporation
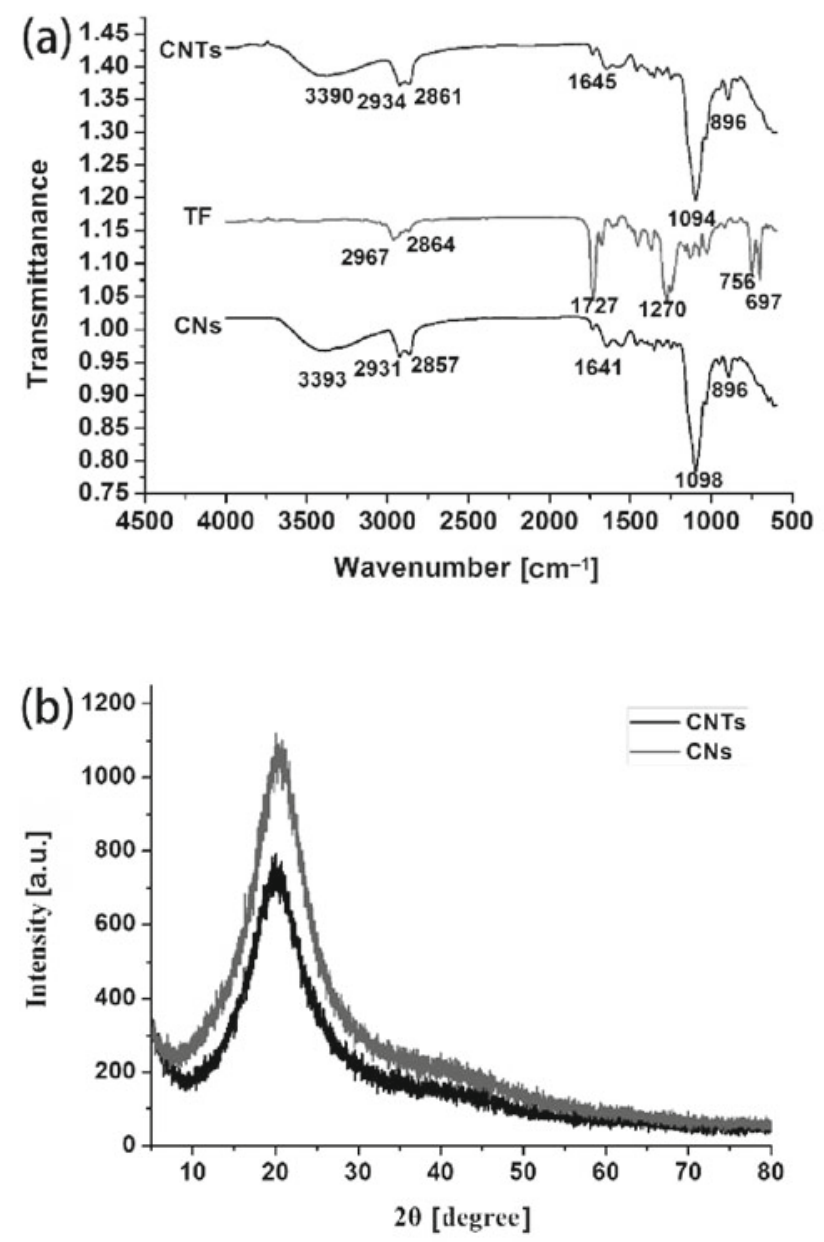

Figure 3. (a) Fourier transform infrared spectra of the TF, CNTs and CNs, (b) X-ray diffraction diagram of CNTs and $\mathrm{CNs}$

of moisture and TF on the surface. The main weight loss occurred at $157-800^{\circ} \mathrm{C}$ and the weight losses of CNTs and CNs were about $83.21 \%$ and $76.44 \%$ respectively, which mainly due to the breakage of hydrogen bonds between the N-acetyl and free amino groups (Grant, Blair, \& McKay, 1990), the depolymerization and decomposition of glucosamine units of CS and weight loss of encapsulated TF and partial wall. The weight loss difference between CNTs and CNs may be caused by TF

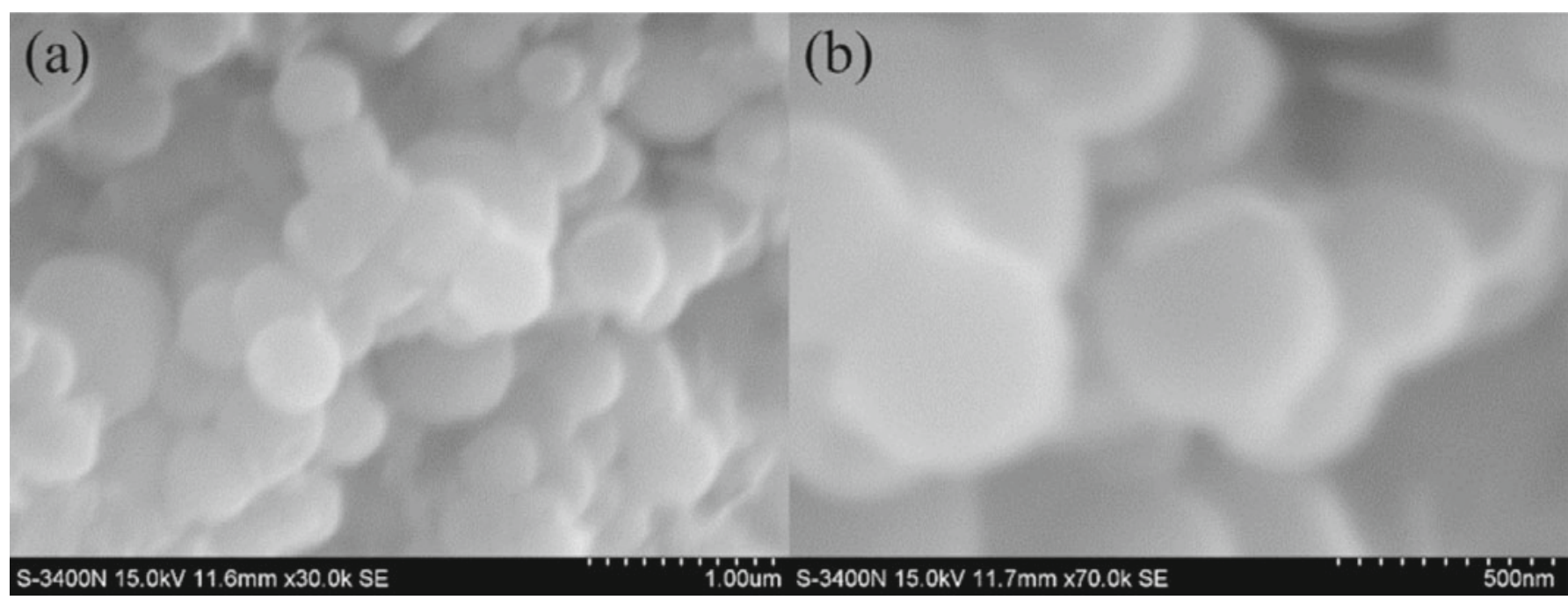

Figure 2. Scanning electron microscopy images of chitosan nanocapsules encapsulated tuberose fragrance 

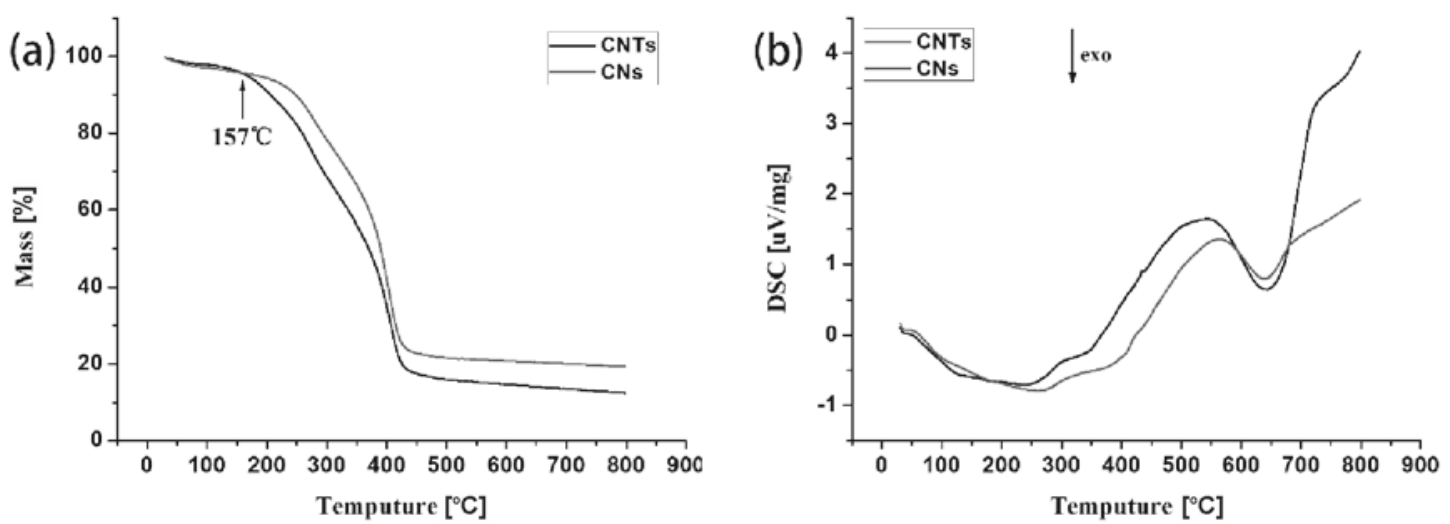

Figure 4. (a) Thermogravimetry diagram and (b) Differential scanning calorimetry diagram of CNTs and CNs

encapsulated in wall materials. The differential scanning calorimetry (DSC) curves of CNTs and CNs were shown in Figure 4(b). Polymer decomposition is endothermic process. At the temperature range of 250 to $550^{\circ} \mathrm{C}$, heat flow of CNTs and CNs are $0.79 \mathrm{uv} / \mathrm{mg}$ and $0.60 \mathrm{uv} / \mathrm{mg}$ respectively. It demonstrated that endothermic value of CNTs is greater than that of CNs at $250-550^{\circ} \mathrm{C}$. This difference may be caused by the evaporation of $\mathrm{TF}$ encapsulated in wall materials.

\section{The rheological properties comparative analysis}

\section{Steady rheological measurements}

The viscosity variation of CNTs emulsion as a function of shear rate was shown in Figure 5 for different TF concentration.

As shown in Figure 5, the apparent viscosity of CNTs emulsion decreases exponentially as a function of shear rate which indicated its non-Newtonian shear thinning (pseudoplastic) behavior. All the CNTs emulsions (TF concentrations are $0.2,0.4,0.6$, and $0.8 \%$ respectively) followed the same trend, exhibiting the shear thinning property. CNTs emulsion was non-Newtonian and it was Newtonian only at high shear rate. Because the nanocapsules were dispersed disorderly in emulsion initially, nanoparticles were elongated along the flow direction under the action of shear field. Due to the space rearrangement of nanocapsules happened in emulsion system, nanocapsules had a directional arrangement. Particle interaction of nanoparticles was reduced gradually, and

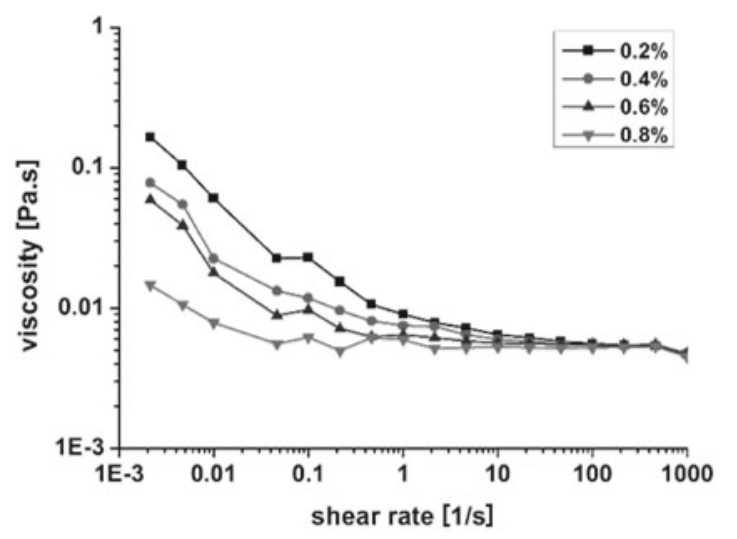

Figure 5. The log-log plots of apparent viscosity as a function of shear rate for CNTs emulsion of different TF concentration energy consumption and the internal friction were decreased accordingly, so flow resistance and apparent viscosity reduced with increasing the shear rate, until stable.

The viscosity data asymptote to a value nearly a decade above the viscosity of water, independent of TF concentration can be observed. This is probably due to that all of the yielding has to do with breaking flocs, and the final suspension has very close to the same volume fraction of a fine emulsion.

Furthermore, note that the results indicated that the decreasing trend of apparent viscosity and the increasing trends of particle size with the increase in TF concentration as showed Figure 1(d). Now assuming that volume fraction was same for CNTs emulsion, the smaller the particle size, the more particles in CNTs emulsion. Interparticle spacing became narrow and gravitational potential energy between particles increased with the decrease of particle size. Due to the relative displacement between the particles is difficult, apparent viscosity showed upward trend with the decrease in particle size. According to the rheology theory of colloid, the higher the concentration of nanofluids, its rheological behavior was deviating from the Newtonian fluid; it means the greater particle size, the smaller slope of viscosity as a function of shear rate.

\section{Strain sweep measurement}

A representative rheogram, showing a linear viscoelastic region (LVR) obtained from a strain sweep experiment, is shown in Figure 6. The dynamic strain sweep for determination of the linear viscoelastic (LVE) region of the emulsions was carried out at a fixed frequency of $0.1-10 \%$. Thereafter, a strain of $1 \%$ within the LVE region was selected for the dynamic frequency sweep measurements with the frequency range from 1 to 1000 $\mathrm{rad} / \mathrm{s}$. The frequency-dependent curves of G" and G' were recorded.

\section{Frequency sweep measurement}

The dynamic rheological measurements were conducted to evaluate the change of the loss modulus and storage modulus at different oscillation frequency. As shown in Figure 7, it clearly revealed that general change of the CNTs emulsion from viscous $\left(G^{\prime \prime}>G^{\prime}\right)$ at low oscillation frequency to moderately elastic $\left(G^{\prime}>G^{\prime \prime}\right)$ at high oscillation frequency, which indicated a little frequency dependence of both moduli. CNTs emulsions of different $\mathrm{TF}$ concentration are from viscous mainly into elastic 


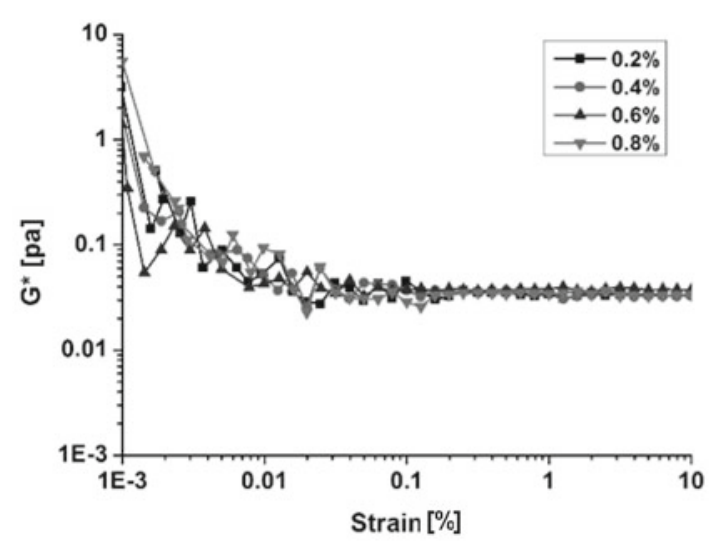

Figure 6. The log-log plots of complex modulus as a function of strain for CNTs emulsion of different TF concentration

with the increase of oscillation frequency. The turning points shift to the lower frequency with the increasing of TF concentration. Due to space rearrangement of nanocapsules was happened in emulsion system when oscillation frequency increased gradually, nanocapsules had a directional arrangement. Particle interaction of nanoparticles was reduced gradually, and energy consumption and the internal friction were decreased accordingly. So flow resistance and viscosity reduced. All the nanocapsules emulsions were from viscous states into elastic states with the increase of oscillation frequency, and only the turning point was in different frequency. The apparent viscous modulus declines with the rise
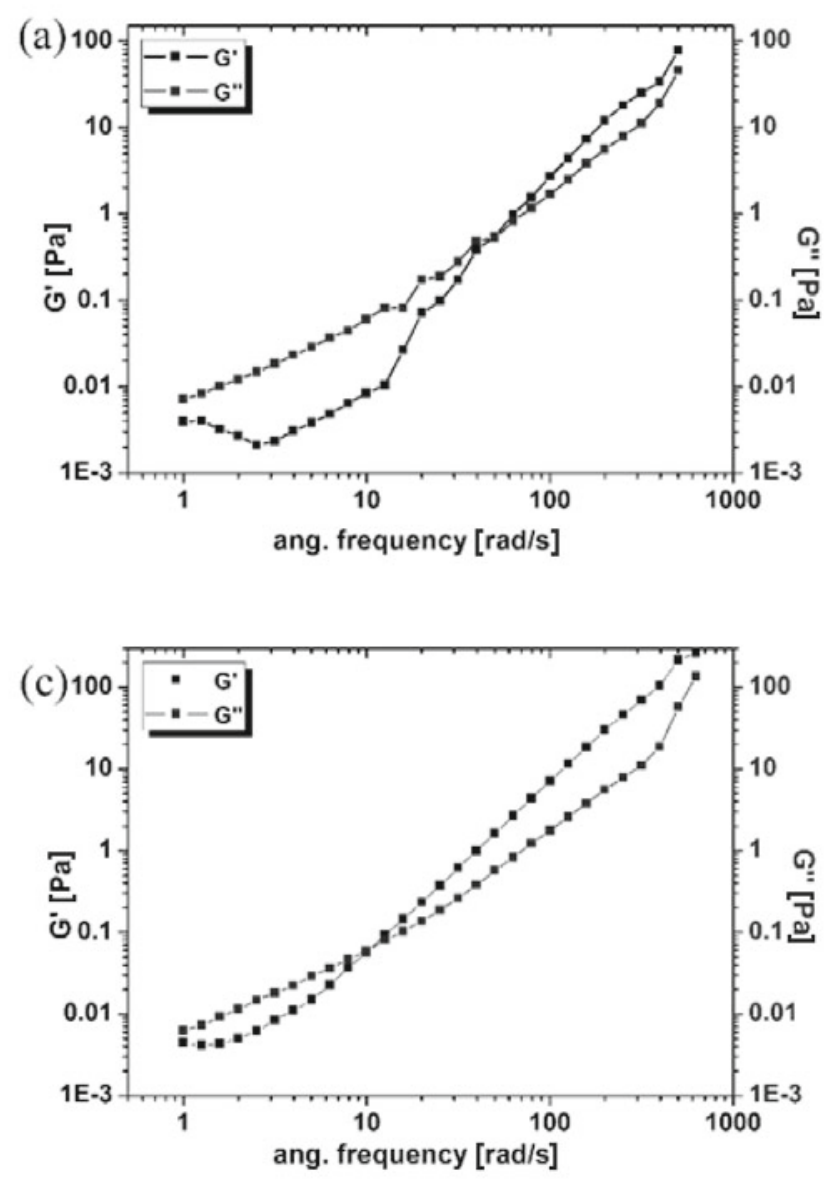

in particle size, so the turning point shifts to the lower frequency with the increase of TF concentration.

Furthermore, it can be observed from the Figure 8 that viscous modulus is basically constant and elastic modulus decreased with increasing of the TF concentration when the oscillation frequency is consistent.

\section{CONCLUSION}

In this work, chitosan nanocapsules encapsulated tuberose fragrances were successfully prepared in $\mathrm{o} / \mathrm{w}$ emulsion via the ionic gelification method. It is concluded that the formation of desirable CNTs is possible by controlling the critical fabricating parameters including CS/TPP mass ratio, $\mathrm{pH}$ value of CS Solution, CS molecular mass and TF concentration. The results show that optimum preparation conditions are as follows: CS/ TPP mass ratio 5:1, $\mathrm{pH}$ of CS solution 4.0, molecular mass of CS $150 \mathrm{kda}$. DLS results demonstrated that the distribution of CNTs was uniform comparatively. SEM showed that CNTs were spherical in shape. The results of FTIR and XRD proved that TF was encapsulated in CS and TPP. The thermal stability of CNTs and CNs was investigated by TGA and DSC.

CNTs emulsion was systematically investigated by steady-state shear and oscillatory shear measurements. Steady-state shear experiment results showed that with the increase of shear rate, CNTs emulsion take on shear-thinning behavior. The viscous modulus of CNTs emulsion decreases with the increase of the TF concentration. Nanoparticle size is of crucial importance
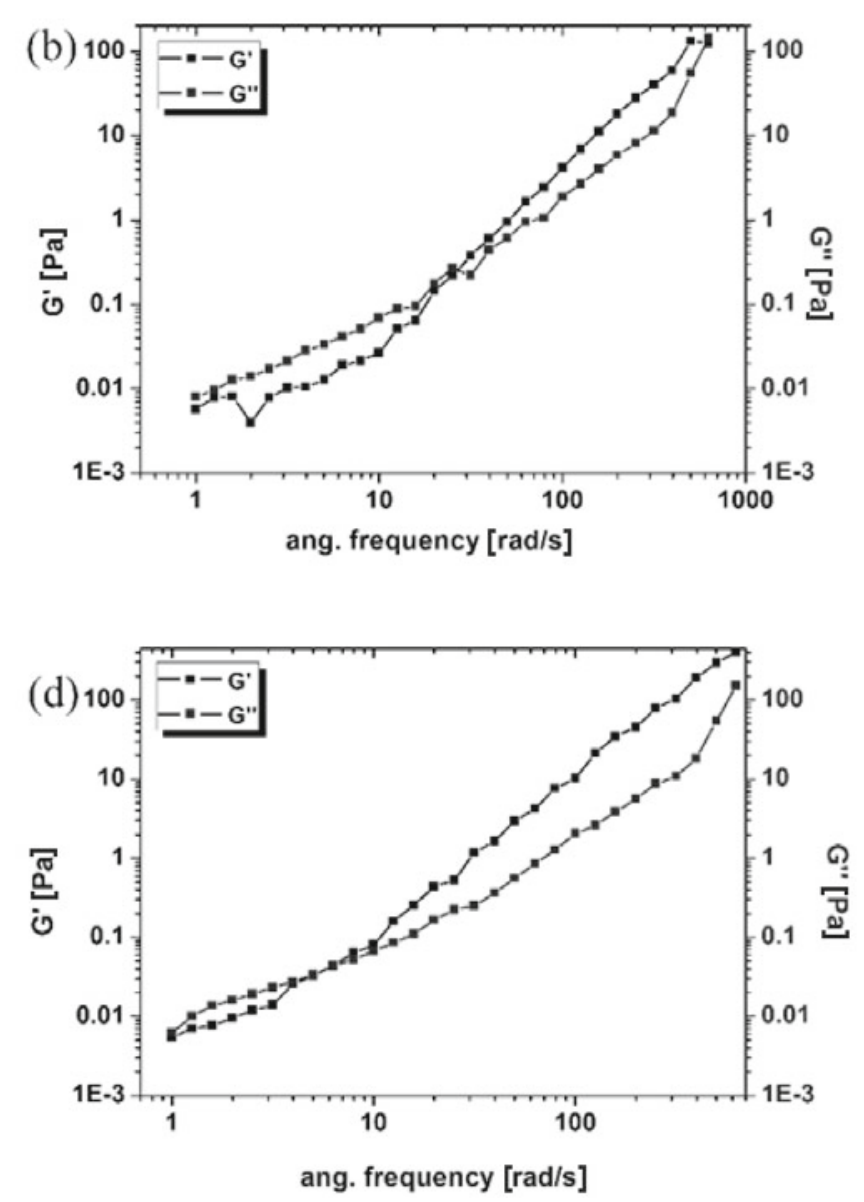

Figure 7. The log-log plots of storage and loss moduli as a function of frequency (1 to $1000 \mathrm{rad} / \mathrm{s}$ ) for CNTs emulsion of different TF concentration. (a) $0.2 \%$; (b) $0.4 \%$; (c) $0.6 \%$; (d) $0.8 \%$ 

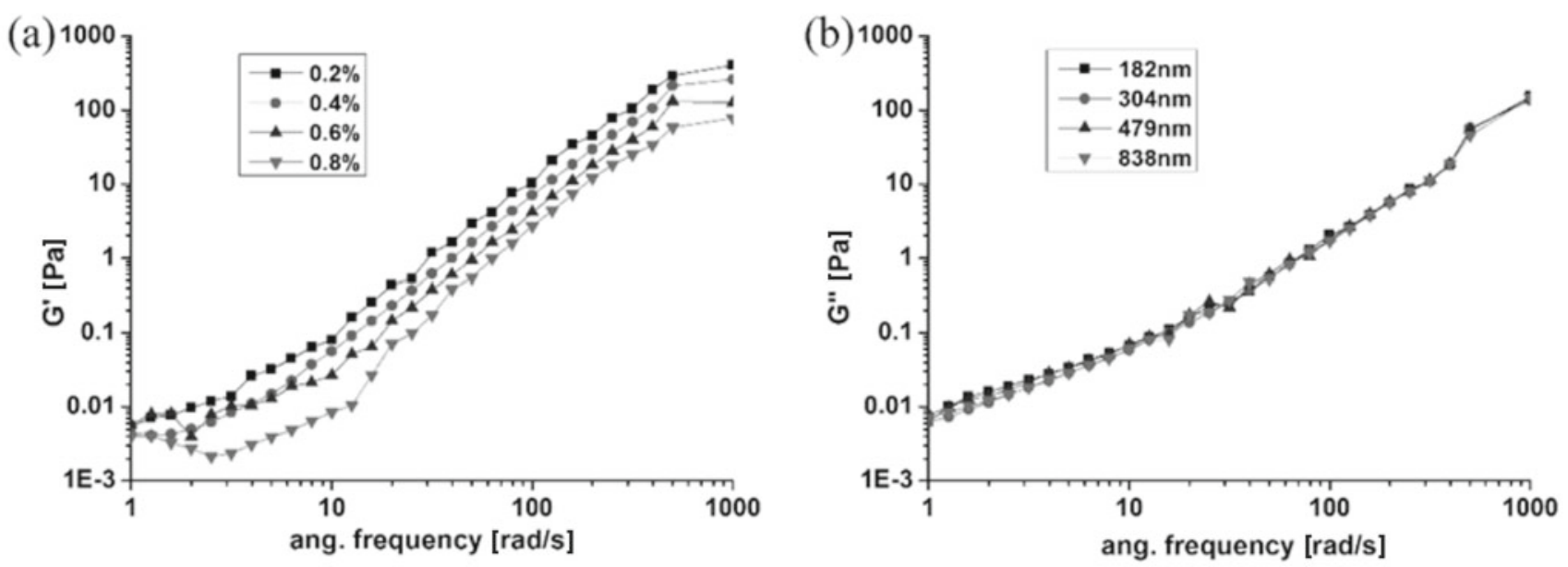

Figure 8. The log-log plots of storage (a) and loss moduli, (b) as a function of frequency ( 1 to $1000 \mathrm{rad} / \mathrm{s}$ ) for CNTs emulsion of different TF concentration

to the viscosity of the CNTs emulsion. The oscillatory shear experimental and simulation results indicated that viscous modulus is basically constant and elastic modulus decreases with increase of the TF concentration. With the increase of the frequency of oscillation, CNTs emulsions of different TF concentration mainly take on viscous state and change into elastic state gradually. The turning points shift to the lower frequency with the increase of TF concentration. Rheological properties are essential to practical applications of CNTs emulsions.

\section{ACKNOWLEDGMENTS}

This work was financially supported by the National Natural Science Fund of China (21276157, 21476140) and the Shanghai Plateau Discipline "Chemical Engineering and Technology (Perfume and Aroma Technology)".

\section{LITERATURE CITED}

1. Zhu, G.Y., Xiao, Z.B., Zhou, R.J. \& Zhu. Y.L. (2014). Study of production and pyrolysis characteristics of sweet orange flavor- $\beta$-cyclodextrin inclusion complex. Carbohyd. Polym. 105, 75-80. DOI: 10.1016/j.carbpol.2014.01.060.

2. Chen, C.K., Law, W.C., Aalinkeelm, R., Yu, Y., Nair, B., Wu, J., Mahajan, S., Reynolds, J.L., Li, Y., Lai, C.K., Tzanakakis, E.S., Schwartz, S.A., Prasad, P.N. \& Cheng, C. (2014). Biodegradable cationic polymeric nanocapsules for overcoming multidrug resistance and enabling drug-gene co-delivery to cancer cells. Nanoscale 6, 1567-1572. DOI: 10.1039/C3NR04804G.

3. El-Gogary, R.I., Rubio, N., Wang, J.T.W., Al-Jamal, W. T., Bourgognon, M., Kafa, H., Naeem, M., Klippstein, R., Abbate, V., Leroux, F., Bals, S., Tendeloo, G.V., Kamel, A.O., Awad, G.A.S., Mortada, N.D. \& Al-Jamal, K.T. (2014). polyethylene glycol conjugated polymeric nanocapsules for targeted delivery of quercetin to folate-expressing cancer cells in vitro and in vivo. ACS Nano 8, 1384-1401. DOI: 10.1021/nn405155b.

4. Xiao, Z.B., Liu, W.L., Zhu, G.Y., Zhou, R.J. \& Niu, Y.W. (2014). Production and characterization of multinuclear microcapsules encapsulating lavender oil by complex coacervation. Flavour Fragr. J. 29, 166-172. DOI: 10.1002/ffj.3192.

5. Alves, N.M. \& Mano, J.F. (2008). Chitosan derivatives obtained by chemical modifications for biomedical and environmental applications. Int. J. Biol. Macromol. 43, 401-414. DOI: 10.1016/j.ijbiomac.2008.09.007.

6. Li, L.H., Deng, J.C., Deng, H.R., Liu, Z.L. \& Xin, L. (2010). Synthesis and characterization of chitosan/ZnO nano- particle composite membranes. Carbohydr. Res. 345, 994-998. DOI: 10.1016/j.carres.2010.03.019.

7. Okamoto, Y., Kawakami, K., Miyatake, K., Morimoto, M., Shigemasa, Y. \& Minami, S. (2002). Analgesic effects of chitin and chitosan. Carbohyd. Polym. 49, 249-252. DOI: 10.1016/S0144-8617(01)00316-2.

8. Anitha, A., Deepa, N., Chennazhi, K. P., Nair, S. V., Tamura, H. \& Jayakumar, R. (2011). Preparation, characterization, in vitro drug release and biological studies of curcumin loaded dextran sulphate-chitosan nanoparticles. Carbohyd. Polym. 83, 66-73. DOI: 10.1016/j.carbpol.2011.01.005.

Zhang, Y.Q., Chen, J.J., Zhang, Y.D., Pan, Y.F., Zhao, J.F., Ren, L.F., Liao, M.M., Hu, Z.Y., Kong, L. \& Wang, J.W. (2007). A novel PEGylation of chitosan nanoparticles for gene delivery. Biotech. Appl Biochem. 46, 197-204. DOI: 10.1042/ BA20060163.

10. Moura, M.R., Aouada, F.A., Avena-Bustillos, R.J., McHugh, T.H., Krochta, J.M. \& Mattoso, L.H. (2009). Improved barrier and mechanical properties of novel hydroxypropyl methylcellulose edible films with chitosan/tripolyphosphate nanoparticles. J. Food Eng. 92, 448-453. DOI: 10.1016/j.jfoodeng.2008.12.015.

11. Jayakumar, R., Menon, D., Manzoor, K., Nair, S.V. \& Tamura, H. (2010). Biomedical applications of chitin and chitosan based nanomaterials-A short review. Carbohyd. Polym. 82, 227-232. DOI: 10.1016/j.carbpol.2010.04.074.

12. Li, Q., Mahendra, S., Lyon, D.Y., Brunet, L., Liga, M. V., Li, D. \& Alvarez, P.J. (2008). Antimicrobial nanomaterials for water disinfection and microbial control: potential applications and implications. Water Res. 42, 4591-4602. DOI: 10.1016/j. watres.2008.08.015.

13. Kim, D.G., Jeong, Y.I., Choi, C., Roh, S.H., Kang, S.K., Jang, M.K., \& Nah, J.W. (2006). Retinol-encapsulated low molecular water-soluble chitosan nanoparticles. Int. J. Phytoremediat. 319, 130-138. DOI: 10.1016/j.ijpharm.2006.03.040.

14. Songsurang, K., Praphairaksit, N., Siraleartmukul, K., \& Muangsin, N. (2011). Electrospray fabrication of doxorubicin-chitosan-tripolyphosphate nanoparticles for delivery of doxorubicin. Arch. Pharm. Res. 34, 583-592. DOI: 10.1007/ s12272-011-0408-5.

15. Xu, Y. \& Hanna, M.A. (2007). Electrosprayed bovine serum albumin-loaded tripolyphosphate cross-linked chitosan capsules: synthesis and characterization. J. Microencapsul. 24, 143-151. DOI: 10.1080/02652040601058434.

16. Chein, R. \& Huang, G. (2005). Analysis of microchannel heat sink performance using nanofluids. Appl. Therm. Eng. 25, 3104-3114. DOI: 10.1016/j.applthermaleng.2005.03.008.

17. Nguyen, C.T., Desgranges, F., Roy, G., Galanis, N., Mare, T., Boucher, S. \& Angue, M.H. (2007). Temperature and par- 
ticle-size dependent viscosity data for water-based nanofluids - Hysteresis phenomenon. Int. J. Heat Fluid Fl. 28, 1492-1506. DOI: 10.1016/j.ijheatfluidflow.2007.02.004.

18. Hobbie, E.K. (2010). Shear rheology of carbon nanotube suspensions. Rheol. Acta 49, 323-334. DOI: 10.1007/s00397009-0422-4.

19. Penkavova, V., Tihon, J. \& Wein, O. (2011). Stability and rheology of dilute $\mathrm{TiO}_{2}$-water nanofluids. Nanoscale Res. Lett. 6, 273-276. DOI: 10.1186/1556-276X-6-273.

20. Chen, H., Ding, Y., Lapkin, A. \& Fan, X. (2009). Rheological behaviour of ethylene glycoltitanate nanotube nanofluids. J. Nanopart. Res. 11, 1513-1520. DOI: 10.1007/ s11051-009-9599-9.

21. Mahbubul, I.M., Saidur, R. \& Amalina, M.A. (2012). Latest developments on the viscosity of nanofluids. Int. J. Heat Mass Tran. 55, 874-885. DOI: 10.1016/j.ijheatmasstransfer.2011.10.021.

22. Tseng, W.J., \& Chen, C.N. (2006). Dispersion and rheology of nickel nanoparticle inks. J. Mater. Sci. 41, 1213-1219. DOI: $10.1007 / \mathrm{s} 10853-005-3659-\mathrm{z}$.

23. Wang, Y., Yang, X.P., Liu, W.T., Zhang, F., Cai, Q. \& Deng, X.L. (2013). Controlled release behaviour of protein-loaded microparticles prepared via coaxial or emulsion electrospray. J. Microencapsul. 30, 490-497. DOI: 10.3109/02652048.2012.752537.

24. Luckham, P.F. \& Ukeje, M.A. (1999). Effect of particle size distribution on the rheology of dispersed systems. J. Col. Inter. Sci. 220, 347-356. DOI: 10.1006/jcis.1999.6515.

25. Stoica, R., Şomoghi, R. \& Ion, R.M. (2013). Preparation of chitosan-tripolyphosphate nanoparticles for the encapsulation of polyphenols extracted from rose hips. Dig. J. Nanomater. Bios. 8, 955-963.

26. Hu, B., Pan, C.L., Sun, Y., Hou, Z.J., Ye, H. \& Zeng, X.X. (2008). Optimization of Fabrication Parameters To Produce Chitosan - Tripolyphosphate Nanoparticles for Delivery of Tea Catechins. J. Agric. Food Chem. 56, 7451-7458. DOI: 10.1021/jf801111c.

27. Papadimitriou, S., Bikiaris, D. \& Avgoustakis, K. (2008). Chitosan nanopart icles loaded with dorzolamide and pramipexole. Carbohyd. Polym. 73, 44-54. DOI: 10.1016/j. carbpol.2007.11.007. 